\title{
Scoping review of patient-centered care approaches in healthcare
}

\author{
Marissa K Constand*, Joy C MacDermid, Vanina Dal Bello-Haas and Mary Law
}

\begin{abstract}
Background: The purpose of this scoping review was to describe how three tenants of patient-centered care provision: communication, partnership, and health promotion are addressed in patient-centered care models/frameworks across the literature.

Methods: A scoping review of literature published in English since 1990 was conducted using Medline, CINAHL, and EMBASE. A key term search strategy was employed using "patient-centered care", "client-centered care", "framework" and "model" to identify relevant studies.

Results: Application of the search strategy resulted in a hit total of 101 articles. Nineteen articles met inclusion criteria, of which 12 were review articles; 5 were qualitative research papers; one was a randomized control trial; and one was a prospective study. From these articles, 25 different patient-centered care frameworks/models were identified.

Conclusions: The fact that all identified approaches to patient-centered care incorporated strategies to achieve effective communication, partnership, and health promotion indicates that clinicians can select a patient-centered approach from the literature that best suits their patient's needs, and be confident that it will satisfy the three core elements of patient-centered care provision. While empirical literature on specific patient-centric frameworks and models was limited, much empiric evidence was sourced for the most consistently defined component of patient-centered care, communication.
\end{abstract}

Keywords: Patient-centered care, Model, Framework

\section{Background}

Patient-centered care in healthcare is defined as care provision that is consistent with the values, needs, and desires of patients and is achieved when clinicians involve patients in healthcare discussions and decisions [1]. The Patient Centered Clinical Method identifies that patientcenteredness is achieved in part by understanding patients experiences with illness and disease as well as understanding patients holistically [2]. Patient-centered care is thought to have many benefits and has been proposed as a means of achieving better health outcomes, greater patient satisfaction, and reduced health costs [2]. For example, Cooper and colleagues [3] have identified that in a population of patients receiving physiotherapy for the treatment of chronic low back pain, the provision of patient-centered care helped the physiotherapists to "better understand and

\footnotetext{
* Correspondence: constamk@mcmaster.ca

School of Rehabilitation Science, McMaster University, 1400 Main Street West, L8S 1C7, Hamilton, Ontario, Canada
}

manage" their patient's needs. Furthermore, Cott [4] identified that an improved understanding of patient needs stems from clinicians acknowledging patient perspectives on recovery.

In a multi-site study conducted in primary care physician's offices servicing members of both urban and rural communities, Little et al. [5] surveyed patient preferences for patient-centered care and suggested that the three main objectives of patient-centered care provision should include effective communication, partnership, and health promotion. Effective communication has been defined as the exploration of the patient's disease and illness to develop an understanding of the patient's healthcare experiences $[1,2]$. Developing a partnership with patients occurs when clinicians and patients find common ground upon which a healthcare plan can be developed mutually [1,2]. Finally, effective health promotion, defined in this study as tailoring healthcare plans based on reflections on the patient's past health history and current health context, helps 
ensure that healthcare plans are developed from an understanding of previous healthcare experiences. This approach reduces the risk of failed treatments and ensures optimal use of resources [1,2]. While these three components of patient-centered care have been identified as the elements that are most valued by patients receiving medical attention [5], the extent to which different patientcentered care frameworks and models embrace these three components as core elements, and their application across different disciplines has not been studied. Although rehabilitation is an area of practice where patient-centered care is seen as "the way forward" [6], even here a consistent conceptual framework or model of patient-centered care has yet to be accepted. Clarity on definitions, frameworks, and essential ingredients of patient-centered care is a prerequisite for developing rigorous empirical evidence evaluating patient-centred care and for insuring fidelity when it is implemented. A scoping review approach provides a methodology for determining the state of the evidence on a topic that is especially useful where issues require clarification before rigorous empirical studies are conducted. Therefore, the purpose of this study is to use Arskey and O'Malley's scoping review methodology to determine the following with respect to patient-centered care frameworks and models:

1. What is the extent and nature of published scientific literature on patient-centered care frameworks and models including the research designs used, areas of clinical practice, and conceptualization of patient-centered care?

2. To what extent do the frameworks and models address the three core components of patientcentered care: effective communication, partnership, and health promotion?

A secondary purpose was to reflect on the depth of evidence surrounding a key component of patient-centered care, effective communication, by charting the published systematic reviews on effective communication practices. This review was conducted as a secondary review in order to identify evidence supporting patient-centered communication that may not be associated with a patient-centered framework or model since effective communication is the most definable and consistent component of patientcentered care.

\section{Methods}

\section{Identifying relevant studies}

Literature published in English between 1990 and 2012 was collected from three databases: Medline, CINAHL, and EMBASE. A key term search strategy was employed using the words "patient-centered care", "client-centered care", "framework" and "model". The terms "framework" and "model" were selected to classify the approaches to patient-centered care provision because they provide standardized methods that can be easily followed and reproduced. A similar search was conducted for systematic reviews that included communication as a title word to identify the most easily accessible systematic reviews addressing communication.

\section{Study selection}

Articles were eligible for inclusion in this review if they described a patient-centered care framework or model being applied to an adult population receiving healthcare. Only articles published since 1990 and written in English were eligible for inclusion in this review. Articles were excluded if they did not pertain to a patient-centered care framework or model, or if did not address a healthcare context. Titles and abstracts of articles were independently reviewed by two authors (MKC and JCM). If articles were representative of the inclusion criteria, the articles went through two full-text independent reviews by two authors (MKC and JCM). If disagreements arose, a third party reviewer would be consulted. A second search was conducted using communication as a keyword, and limiting the retrieval to systematic reviews using Clinical Queries in Medline, and the term systematic review in other databases. Articles were included from the secondary review of the literature if they were systematic reviews identifying effective communication strategies in any healthcare discipline. Studies were excluded if they did not identify communication strategies between clinicians and patients or families.

\section{Charting data}

If an article was eligible for inclusion in this study, data related to the patient-centered care framework or model presented in the article was extracted by the lead author and reviewed by a second author (JCM). Data extracted from the reviewed patient-centered care frameworks and models was entered into data extraction records and synthesized in summary format. Data were systematically charted using the data charting form developed in Microsoft Excel. Information on authorship, article type, population, and patientcentered care approach were recorded on this form. A second data charting form was developed to chart data on the communication systematic reviews identified. Information on clinical context, patient-centered care focus, number of studies reviewed and key findings were recorded on this form.

\section{Collating, summarising and reporting results}

Information that was organized on the data charting forms was employed to collate and report the articles' approaches towards achieving effective communication, partnership, and health promotion. 


\section{Results}

From an original hit total of 101 articles, 60 articles were excluded after reading the article title, and 22 articles were excluded after they were read fully (Figure 1). Nineteen articles were selected for inclusion in this review. Twelve of these articles were narrative review articles. The remaining studies included four qualitative research papers, one randomized control trial, and one prospective study. Of the 19 included articles, 25 unique patient-centered care frameworks or models were identified (Table 1). The secondary review conducted on communication strategies yielded a hit total of 69 systematic review articles, 25 of which met inclusion criteria (Table 2).

\section{Analysis}

Content analysis of all patient-centered care frameworks and models included in this review revealed that all frameworks and models included approaches to achieving the three essential components of patient-centered care: effective communication, partnership, and health promotion (Table 3).

\section{Communication}

Three components of communication were commonly discussed in the articles reviewed: a) sharing information, b) compassionate and empowering care provision, and c) sensitivity to patient needs.

\section{Sharing information}

Creation of an effective learning environment was cited as a method for supporting patient-centered care in $89.5 \%$ of articles reviewed. Many articles discussed effective communication of healthcare information from the clinician to the patient, but also included approaches to effective patient information uptake by the clinician. Effective information uptake was seen as being an essential step in tailoring information to suit patient needs, vulnerabilities, and capacities $[11,12]$. Active listening, asking open ended questions, and developing functional goals were strategies cited by review articles to achieve effective information uptake $[11,12,15]$.

\section{Compassionate and empowering care provision}

Providing compassionate and empowering care was cited as a component of achieving effective communication in $53 \%$ of articles reviewed. Such care is described as being attentive and altruistic, and was emphasized by several review articles and by the sole randomized control trial included in this review $[14,16]$. As well, these articles described compassionate and empowering care as contributing to the development of a strong clinician-patient relationship based upon patient feelings of autonomy and trust $[14,16]$.

\section{Sensitivity to patient needs}

Strategies on how to be sensitive to patient needs were primarily discussed in the qualitative research articles included in this review. Such strategies included acknowledging and adapting to unique patient identifiers $[19,24,25]$. For example, clinicians are urged to observe and reflect on fluctuating levels of patient alertness, patient comfort levels in the presence or absence of family members, and different communication barriers such as hearing loss, in order to facilitate clinical interactions $[15,19,22]$. Of the articles reviewed, $58 \%$ identified that careful observation of unique patient characteristics is necessary to providing care that will lead to optimal patient receptiveness and positive health outcomes.

\section{Partnership}

Two components of partnership development were commonly discussed in the articles reviewed: a) relationship building and b) inter-professional collaboration.

\section{Relationship building}

Relationship building was discussed by all article types included in this review. Of the articles reviewed, 74\% identified that building relationships with patients and families contributes to understanding what problems the patient is most concerned with and how their illness or injury has affected their life $[15,18,23]$. The involvement of patients and families in their care builds trust and encourages mutual problem solving [17].

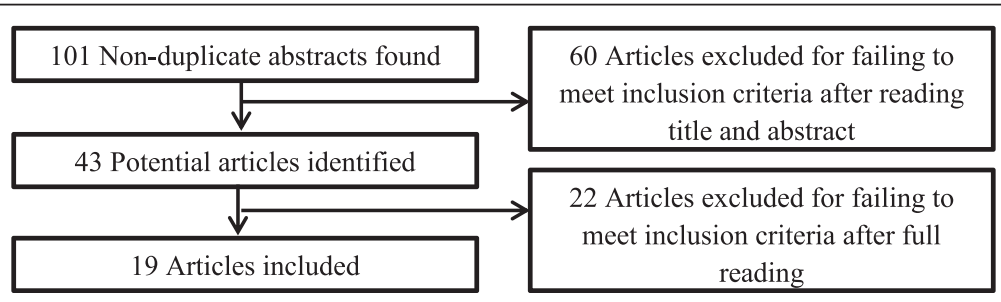

Figure 1 Scoping review process. 
Table 1 Scoping review included articles

\begin{tabular}{|c|c|c|c|}
\hline Author & Article type & Population & Patient-centered care approach identified \\
\hline Ballweg [7] & Review article & Neonatal Intensive Care Unit & $\begin{array}{l}\text { Developmentally Supportive, } \\
\text { Family-Centered Care Model }\end{array}$ \\
\hline Berger [8] & Review article & Psychiatry & The Tidal Model \\
\hline Bickler [9] & Review article & Surgery & Patient-Focused Care Model \\
\hline Boltz [10] & Review article & Geriatrics & Nurses Improving Care for Health System Elders \\
\hline Booth \& MacBride [1 1] & Review article & Generic & Patient-Centered Clinical Method \\
\hline \multirow[t]{5}{*}{ Briggs [12] } & Review article & Palliative Care/ & National Consensus Project for Quality Palliative Care \\
\hline & & Physical Therapy/ & \\
\hline & & End of Life Care & Hypothesis Oriented Algorithm for Clinicians \\
\hline & & & $\begin{array}{l}\text { Framework for Rehabilitation of } \\
\text { Neurodegenerative Diseases Framework for } \\
\text { Assessment in Oncology Rehabilitation }\end{array}$ \\
\hline & & & Models of Practice in Palliative Care \\
\hline Browne et al. [13] & Review article & Nursing & Decentralization \\
\hline Cox [14] & Review article & Psychiatry & Biopsychosocial Model \\
\hline deLusignan et al. [15] & Review article & Nursing & $\begin{array}{l}\text { Model for Patient-Centered Consultations } \\
\text { with Nurses in Primary Care }\end{array}$ \\
\hline DiGoia et al. [16] & Prospective study & Orthopedics & Patient and Family Centered Collaborative Care \\
\hline Enguidanos et al. [17] & Randomized control trial & Geriatrics/Psychiatry & Integrated Depression Care Management Model \\
\hline Ford et al. [18] & Review article & Nursing & RNAO Best Practice Guideline on Client Centered Care \\
\hline \multirow[t]{3}{*}{ Hantho et al. [19] } & Review article & General & Malterud's Key Questions \\
\hline & & & Stuart's BATHE Model \\
\hline & & & The Communication Model \\
\hline Hatzichristou \& Tsimtsiou [20] & Review article & Urology & $\begin{array}{l}\text { Patient Centered Model for the } \\
\text { Management of Sexual Dysfunction }\end{array}$ \\
\hline Kelleher [21] & Review article & Intensive Care & The Synergy Model \\
\hline Kibicho \& Owczarzak [22] & Qualitative research & Pharmacy & Patient-Centered Pharmacy Services \\
\hline McCormack [23] & Qualitative research & Geriatrics & Authentic Consciousness \\
\hline Rosvik et al. [24] & Qualitative research & Geriatrics & VIPS Practice Model \\
\hline van der Eijk et al. [25] & Qualitative research & Neurology & $\begin{array}{l}\text { Theoretical Model of Patient Centeredness } \\
\text { for Parkinson's Disease }\end{array}$ \\
\hline
\end{tabular}

\section{Inter-professional collaboration}

Engaging in inter-professional collaboration to decentralize health care provision was cited as a method of achieving partnership among healthcare professionals in $79 \%$ of the articles reviewed. These articles were primarily review articles that described decentralization as a team-based approach to care provision that contributed to efficient and focused care provision [7-10,13,21].

\section{Health promotion}

Achieving health promotion in a patient-centered context requires reflection on how to best support optimal health and care provision through reflection on the patient's history. The two components of health promotion that were commonly discussed in the articles reviewed as being effective ways to achieve patient-centered care were: a) effective case management and b) efficient use of resources.

\section{Effective case management}

Effective case management was identified by $79 \%$ of articles reviewed as being a necessary component of health promotion. Effective case management involves the evaluation of past successes and failures of care in order to best tailor future health initiatives and reduce risk of adverse health outcomes [26]. This process is facilitated by discussions with patients about previous healthcare experiences in order to develop an understanding of how patients respond to certain types of care, such as care requiring follow-up appointments or self-directed home exercises $[17,19,20]$.

\section{Efficient use of resources}

Appropriate organization of resources around patients was cited by $47 \%$ of articles included in this review as a way to achieve health promotion. By using resources that 
Table 2 Systematic reviews on communication in healthcare

\begin{tabular}{|c|c|c|c|c|}
\hline Systematic review & Clinical context & $\begin{array}{c}\text { PCC } \\
\text { focus }\end{array}$ & $\begin{array}{l}\text { \# Studies } \\
\text { reviewed }\end{array}$ & Key findings \\
\hline Beck, Daughtridge \& Sloane [29] & Primary Care & Yes & 22 & $\begin{array}{c}\text { - Physician behavior linked with } \\
\text { positive patient outcomes, adherence, } \\
\text { and patient satisfaction }\end{array}$ \\
\hline \multirow[t]{2}{*}{ Chan et al. [30] } & Pre-operative Care & Yes & 11 & $\begin{array}{l}\text { - Sharing information, family involvement, } \\
\text { autonomy, and professionalism are key }\end{array}$ \\
\hline & & & & $\begin{array}{l}\text { - Knowledgeable clinicians with positive } \\
\text { attitudes enhance patient "journey" }\end{array}$ \\
\hline Davis et al. [31] & Oncology & Yes & 21 & $\begin{array}{l}\text { - Complementary and alternative medicine } \\
\text { use in patients with cancer must be discussed } \\
\text { using effective communication skills in order } \\
\text { to avoid patients failing to disclose use with clinician }\end{array}$ \\
\hline
\end{tabular}

Edwards et al. [32]

Edwards et al. [33]

Egan et al. [34]

Eggenberger, Heimerl \& Bennett [35]

Fawole et al. [36]

Finke, Light \& Kitko [37]

Hancock et al. [38]

Harrington, Noble \& Newman [39]

Henry et al. [40]

Janssen \& Largo-Janssen [41]

Oliveira et al. [43]

Parker et al. [44]
Laidsaar-Powell et al. [42]

Genetics

Primary Care

Alzheimer's Disease

Dementia

Yes

Palliative Care

Yes

Nursing

Not Clear

Palliative Care

Not Clea

Primary Care

Yes

25

Primary Care

Yes

26

Gynecology

Yes

Primary Care

Yes

Primary Care

Yes

27

Palliative Care Not Clear

123

Pinto et al. [45]
Rehabilitation
- Clinician provision of support and sharing emotion proven to be more beneficial to patients than sharing information

- Including patients in risk estimates during discussion between patients and clinicians regarding genetic screening results is productive

- Employing memory aids and specific caregiver training programs enhances verbal communication, specifically information uptake with patients with Alzheimer's Disease

- Enhancing communication skills of professionals working with dementia patients results in improvements of patient quality of life, positive interactions with peers, and organization of care

- Improving palliative care communication with patients includes improving healthcare utilization and patient/family consultations

- Improving communication between nurses and non-verbal patients is necessary to reduce patient frustration

- Patients' perceptions of shared information are inconsistent with healthcare professional's perceptions of the information provided

- Healthcare professionals "underestimate" patient need for information and "overestimate" patient understanding of illness

- Improvements in perceptions of autonomy impacts information recall, adherence, attendance, and clinical outcomes following intervention studies aimed to augment patient participation in medical interactions

- Increased patient satisfaction was correlated with positive/warm clinician interactions with active listening

- Patient-centered communication styles increase patient satisfaction

- Triadic communication (patient-clinician-family member) involves: encouraging family involvement in care, re-enforcing positive family contributions, identifying roles of patients and family members

- Communication indicating valuing patient autonomy is correlated with high patient satisfaction

- At end-of-life, patients want less information sharing and caregivers want more information sharing

- Patients value empathic and honest clinicians who encourage questions and facilitate discussions

- The "therapeutic alliance" is enhanced by emotional support provision and patient participation during consultation 
Table 2 Systematic reviews on communication in healthcare (Continued)

\begin{tabular}{|c|c|c|c|c|}
\hline Rodin et al. [46] & Oncology & Yes & 21 & $\begin{array}{c}\text { - Patients have varying communication needs } \\
\text { and may prefer professional-centric communication } \\
\text { over patient-centered communication, therefore clinicians } \\
\text { are encouraged to individualize their } \\
\text { communication styles to patient needs }\end{array}$ \\
\hline Scheunemann et al. [47] & Intensive Care & Yes & 2841 & $\begin{array}{l}\text { - Printed communication aids, structured communication } \\
\text { from the healthcare team, and ethics consultations } \\
\text { improve emotional outcomes for families in the ICU }\end{array}$ \\
\hline Slort et al. [48] & Palliative Care & Yes & 15 & $\begin{array}{l}\text { - Clinician availability and openness to facilitating } \\
\text { discussions about end-of-life care, including } \\
\text { reflection on poor outcomes, facilitates } \\
\text { patient-clinician communication }\end{array}$ \\
\hline \multirow[t]{2}{*}{ Tay, Hegney \& Ang [49] } & \multirow[t]{2}{*}{ Nursing } & \multirow[t]{2}{*}{ Not Clear } & \multirow[t]{2}{*}{8} & $\begin{array}{l}\text { - While patient and clinician characteristics are found } \\
\text { to influence communication, the role of the environment } \\
\text { in effective communication between these } \\
\text { two parties is not well documented }\end{array}$ \\
\hline & & & & $\begin{array}{c}\text { - Reception to patient cues and effective information } \\
\text { sharing builds relationships with patients and } \\
\text { maintains open communication }\end{array}$ \\
\hline \multirow[t]{2}{*}{ Thompson \& McCabe [50] } & \multirow[t]{2}{*}{ Psychiatry } & \multirow[t]{2}{*}{ Not Clear } & \multirow[t]{2}{*}{23} & $\begin{array}{l}\text { - A strong clinician-patient relationship } \\
\text { that involves effective communication } \\
\text { is correlated with adherence }\end{array}$ \\
\hline & & & & $\begin{array}{l}\text { - Clinicians wishing to promote patient-clinician } \\
\text { collaboration must attempt to find common } \\
\text { ground with patients and share } \\
\text { decision making roles }\end{array}$ \\
\hline Uitterhoeve et al. [51] & Oncology & Not Clear & 7 & $\begin{array}{l}\text { - No correlation was found between } \\
\text { effective communication training } \\
\text { and patient distress outcomes }\end{array}$ \\
\hline Vasse et al. [52] & Dementia & Not Clear & 19 & $\begin{array}{l}\text { - Improving communication with patients } \\
\text { with dementia can improve daily care } \\
\text { activities and intervention outcomes; however, } \\
\text { has little impact on neuropsychiatric symptoms }\end{array}$ \\
\hline Wanyonyi \& Themessl-Huber [53] & Primary Care & Yes & 6 & $\begin{array}{l}\text { - Clinicians should allocate time to "discover } \\
\text { their patients' psycho-social characteristics" } \\
\text { in order to achieve health promotion }\end{array}$ \\
\hline
\end{tabular}

best suit patient needs and values, clinicians can tailor treatment plans to best represent how patients are likely to respond to certain interventions [16].

\section{Secondary review analysis of communication strategies}

The secondary review of systematic review articles on communication strategies in healthcare revealed that the majority of articles (68\%) explicitly related communication strategies to patient-centered care. Articles that did not explicitly state this relationship through the use of the terms "patient-centered" or "client-centered" care, implied this relationship by identifying how effective communication between patients and healthcare professionals impacts patient satisfaction and health outcomes. The breadth of disciplines from which this literature was found is consistent with the diverse nature of the literature found on patient-centered care frameworks and models. Exploration of key findings revealed that effective communication strategies surrounding information provision and uptake by the healthcare professional, as well as respect for patient autonomy were the main facilitators of a positive clinical interaction.

\section{Discussion}

This scoping review provides an overview of how patientcentered care is conceptualized in the current literature and suggests that the three components of patient-centered care valued by patients are predominantly featured in patientcentered care models and frameworks across different settings, populations, and applications. These core components were approaches to achieving effective communication, partnership and health promotion. While some of the articles reviewed pertained to specific target populations, the frameworks and models that they described were based on similar components of patient-centered care provision. This suggests that the models can be broadly applied. These components were clearly defined by authors, which made common approaches to communication, partnership, and health promotion easily identifiable during the progression of this scoping review's analysis. 
Table 3 Data summary form

\begin{tabular}{|c|c|c|c|c|c|c|c|}
\hline \multirow[b]{2}{*}{ Article } & \multicolumn{2}{|c|}{ Communication } & \multicolumn{2}{|c|}{ Partnership } & \multicolumn{3}{|c|}{ Health promotion } \\
\hline & $\begin{array}{c}\text { Sharing } \\
\text { information }\end{array}$ & $\begin{array}{c}\text { Compassion/empathy/ } \\
\text { empowerment }\end{array}$ & $\begin{array}{l}\text { Sensitivity } \\
\text { to needs }\end{array}$ & $\begin{array}{c}\text { Relationship } \\
\text { building }\end{array}$ & Collaboration & Case management & Resource use \\
\hline Ballweg [7] & & & $x$ & & & $x$ & $x$ \\
\hline Berger [8] & & & & & & & $\mathbf{x}$ \\
\hline Bickler [9] & & & $\mathbf{x}$ & $\mathbf{x}$ & & & $\mathbf{x}$ \\
\hline Boltz [10] & & $\mathbf{x}$ & & $\mathbf{x}$ & & $x$ & $\mathbf{x}$ \\
\hline Booth \& MacBride [11] & & $\mathbf{x}$ & $\mathbf{x}$ & $\mathbf{x}$ & & & $\mathbf{x}$ \\
\hline Briggs [12] & & $\mathbf{x}$ & $\mathbf{x}$ & $\mathbf{x}$ & & & $\mathbf{x}$ \\
\hline Browne et al. [13] & $\mathbf{x}$ & $\mathbf{x}$ & & & & $\mathbf{x}$ & $\mathbf{x}$ \\
\hline Cox [14] & & & $x$ & & & & \\
\hline deLusignan et al. [15] & & & & & & $x$ & $\mathbf{x}$ \\
\hline DiGoia et al. [16] & & & & $\mathbf{x}$ & & & \\
\hline Enguidanos et al. [17] & & & $\mathbf{x}$ & & & & $\mathbf{x}$ \\
\hline \multicolumn{8}{|l|}{ Ford et al. [18] } \\
\hline \multicolumn{8}{|l|}{ Hantho et al. [19] } \\
\hline $\begin{array}{l}\text { Hatzichristou \& } \\
\text { Tsimtsiou [20] }\end{array}$ & & & $\mathbf{x}$ & & $\mathbf{x}$ & & $\mathbf{x}$ \\
\hline \multicolumn{8}{|l|}{ Kelleher [21] } \\
\hline \multicolumn{8}{|c|}{ Kibicho \& Owczarzak [22] } \\
\hline McCormack [23] & $\mathbf{x}$ & & & & $\mathbf{x}$ & & \\
\hline Rosvik et al. [24] & & & & & $x$ & & \\
\hline van der Eijk et al. [25] & & & $\mathbf{x}$ & & $x$ & & \\
\hline Total & $17 / 19$ & & $11 / 19$ & $14 / 19$ & $15 / 19$ & $15 / 19$ & 9/19 \\
\hline \multicolumn{8}{|l|}{ Incorporates category } \\
\hline $\begin{array}{l}\text { Does not incorporate } \\
\text { category }\end{array}$ & $x$ & & & & & & \\
\hline
\end{tabular}

Epstein et al. [26] identify that while patient-centered care is acknowledged by clinicians as an ideal approach to care provision, "what it is and how to measure it" [26] is not clear to clinicians. They suggest that additional research is needed to strengthen the evidence supporting patient-centered care in healthcare [26]. This scoping review provides a foundation for future research by collating and summarizing the theoretical and empirical evidence regarding effective approaches to achieving patientcentered care provision. There is clearly a need for greater emphasis on empirical testing of the health and system impacts of providing patient-centered care in different contexts since the literature reviewed primarily addressed this topic theoretically, and only one randomized control trial was identified. Despite this finding, the consensus around inclusion of communication, partnership, and health promotion, across frameworks identified through this scoping review provides preliminary support that these key features of patient-centered care should be specifically included and evaluated in future studies or in clinician training.
The use of theoretical foundations is considered important in in complex health care issues, but theory has been operationalized more conceptually than empirically within the literature on patient-centered care, as indicated by the fact that only one randomized control trial was identified. This is consistent with findings of how theory has been applied to knowledge translation within the field of rehabilitation. Colquhoun et al. [27] found theoretical frameworks were more commonly used in a generic way rather than as a specific operational tool for defining interventions, processes, expected outcomes or evaluation strategies. Charting the nature of the evidence with respect to the use of patient-centered care frameworks and models suggests a greater need for empirical studies that test the value of providing patient-centered care versus alternatives in a rehabilitation context. Explicit use of the theory would ideally be integrated throughout training processes, materials that operationalize patient-centered care, evaluative instruments that assess its implementation, and all research that seeks to understand how it affects the process and outcomes of care. 
Having found a consensus that communication, partnership and health promotion are key aspects to providing patient-centered care, it is important to have rigorous definitions and clear descriptions of what these processes entail, as well as evidence about how to operationally optimize these elements in different contexts and with different patient populations. This study highlighted a rich body of evidence to inform our understanding of communication. However, health promotion and partnership have a generic meaning that is quite broad, as they have been divided as having specific characteristics within patientcentered care. This may cause confusion for clinicians who believe that they are practicing these components of patient-centered care, as their approach may be consistent with the generic meaning of patient-centered care, but inconsistent with the specific steps and components required to operationalize them in a patient-centered way. Thus, fidelity in patient-centered processes may be lost when the concept is disseminated or scaled-up. Furthermore, the lack of consistency between the meaning of health promotion within patient-centered care and other aspects of healthcare warrants further consideration.

It may be that a more inclusive but specific definition would improve this component of patient centered care. For example, health promotion has been defined by the World Health Organization as "the process of enabling people to increase control over their health and its determinants, and thereby improve their health" [28]. However, within the patient-centered care literature it has been defined as developing healthcare plans based on reflection on patient histories for the purposes of health enhancement, risk reduction, and early detection of illness [5]. There are areas of conceptual consensus across these definitions that suggest they promote a common approach [29-53]. However, the patientcentered care definition implicitly refers to the clinical interaction and goals; whereas, the World Health Organization places greater emphasis on determinants of health. Differences in conceptual framing of health promotion make it difficult to isolate studies that investigate the effect of this component of patient-centered care on outcomes. Conversely, there are a substantial number of systematic reviews that name communication as a key focus (in their title) suggesting that communication strategies can be improved by accessing high quality, empirical evidence. This reflects the importance of communication in most aspects of healthcare, and that it is studied as an important concept even where not framed within a patient-centered care framework. From these studies, we were able to determine that the majority of articles published on effective communication strategies in healthcare have a patient-centered focus and that improved outcomes can be expected when health services are designed to implement such strategies.

\section{Conclusion}

While no unifying patient-centered care framework/model was found, a consensus among frameworks and models of different disciplines suggest that three components of patient-centered care have been consistently recognized as critical to the process. Health promotion, communication and partnership have been considered across multiple areas of clinical practice although rarely through empirical studies. This consensus suggests a broadly applicable framework/model of patient-centered care is feasible and together with appropriate operational definitions might advance future empirical studies addressing whether patient-centered care improves outcomes. Studies that attest to the implementation and empirical evaluation of the outcomes of patient-centered care are needed and should at minimum include and measure the three tenets of patient-centered care: communication, partnership, and health promotion.

\section{Competing interests}

The authors declare that they have no competing interests.

\section{Authors' contributions}

This study was completed as part of the graduate thesis work of MKC who was the principal investigator in this study. MKC and JCM collaborated to create a study design to answer the research questions posed. MKC conducted the scoping review and JCM acted as the second reviewer. VDBH and $M L$ assisted in the review and feedback process during the final production of this manuscript and also acted as supervisory committee members of MKC. JCM served as MKC's graduate supervisor. All authors read and approved the final manuscript.

Received: 22 April 2014 Accepted: 16 June 2014

Published: 19 June 2014

\section{References}

1. Mead N, Bower P: Patient-centredness: a conceptual framework and review of the empirical literature. Soc Sci Med 2000, 51:1087-1110.

2. Stewart M, Belle Brown J, Weston WW, McWhinney IR, McWilliam CL, Freeman TR: Patient-Centered Medicine Transforming the Clinical Method. 2nd edition. Abingdon: Radcliffe Medical Press; 2003.

3. Cooper K, Smith BH, Hancock E: Patient-centredness in physiotherapy from the perspective of the chronic low back pain patient. Physiotherapy 2008, 94:244-252.

4. Cott CA: Client-centred rehabilitation: client perspectives. Disabil Rehabil 2004, 16:1411-1422.

5. Little P, Everitt H, Williamson I, Warner G, Moore M, Gould C, Ferrier K, Payne S: Preferences of patients for patient centred approach to consultation in primary care: observational study. BMJ 2001, 322:468-472.

6. Gzil F, Lefeve C, Cammelli M, Pachoud B, Ravaud JF, LePlege A: Why is rehabilitation not yet fully person-centered and should it be more person-centered? Disabil Rehabil 2007, 29:1616-1624.

7. Ballweg DD: Implementing developmentally supportive family-centered care in the newborn intensive care unit as a quality improvement initiative. J Perinat Neonat Nurs 2001, 15:58-73.

8. Berger JL: Incorporation of the Tidal Model into the interdisciplinary plan of care-a program quality improvement project. J Psychiatr Mental Health Nurs 2006, 13:464-467.

9. Bickler B: Putting patient-focused care into practice. AORN J 1994, 60:242-245

10. Boltz M: A system-level approach to improving the care of the older critical care patient. AACN Adv Crit Care 2011, 22:142-149.

11. Booth BJ, McBride T: Patient focus and the quality framework. Aust Fam Physician 2007, 36:20-22.

12. Briggs RW: Clinical decision making for physical therapists in patient-centered end of life care. Top Geriatr Rehabil 2011, 27:10-17.

13. Browne R, Miller E: Leading Your Leader. Nurse Manage 2003, 34:58-62. 
14. Cox JL: Empathy, identity and engagement in person-centred medicine: The sociocultural context. J Eval Clin Pract 2011, 17:350-353.

15. de Lusignan S, Wells S, Russell C: A model for patient-centred nurse consulting in primary care. BJN 2003, 12:85-90.

16. DiGioia A, Greenhouse PK, Levison TJ: Patient and family-centered collaborative care: An orthopaedic model. Clin Orthop Rel Res 2007, 463:13-19.

17. Enguidanos $S M$, Davis $C$, Katz $L$ : Shifting the paradigm in geriatric care management: Moving from the medical model to patient-centered care. Soc Work Health Care 2005, 41:1-16.

18. Ford PE, Rolfe S, Kirkpatrck H: A journey to patient-centered care in Ontario, Canada: Implementation of a best-practice guideline. CNS 2011, 25:198-206.

19. Hantho A, Jensen L, Malterud K: Mutual understanding: A communication model for general practice. Scand J Prim Health Care 2002, 20:244-251.

20. Hatzichristou D, Tsimtsiou Z: Prevention and management of cardiovascular disease and erectile dysfunction: Toward a common patient-centered, care model. Am J Cardiol 2005, 96:80M-84M.

21. Kelleher S: Providing patient-centred care in an intensive care unit. Nurs Stand 2006, 21:35-40.

22. Kibicho J, Owczarzak J: A patient-centered pharmacy services model of HIV patient care in community pharmacy settings: A theoretical and empirical framework. AIDS Patient Care ST 2012, 26:20-28.

23. McCormack B: A conceptual framework for person-centred practice with older people. Int J Nurs Pract 2003, 9:202-209.

24. Rosvik J, Kirkevold M, Engedal K, Brooker D, Kirkevold O: A model for using the VIPS framework for person-centred care for persons with dementia in nursing homes: A qualitative evaluative study. Int J Older People Nurs 2011, 6:227-236

25. van der Eijk M, Faber MJ, Al Shamma S, Munneke M, Bloem BR: Moving towards patient-centered healthcare for patients with Parkinson's disease. Parkinsonism Relat Disord 2011, 17:360-364.

26. Epstein RM, Franks P, Fiscella K, Shields CG, Meldrum SC, Kravitz RL, Duberstein PR: Measuring patient-centered communication in patient-physician consultations: theoretical and practical issues. Soc Sci Med 2005, 61:1516-1528

27. Colquhoun HL, Letts LJ, Law MC, MacDermid JC, Missiuna CA: A scoping review of the use of theory in studies of knowledge translation. CJOT 2010, 77:270-279.

28. World Health Organization: [http://www.who.int/topics/health_promotion/en/

29. Beck RS, Daughtridge R, Sloane PD: Physician-patient communication in the primary care office: a systematic review. J Am Board Fam Med 2002, 15:25-38.

30. Chan Z, Kan C, Lee P, Chan I, Lam J: A systematic review of qualitative studies: patients' experiences of preoperative communication. J Clin Nurs 2012, 21:812-824.

31. Davis EL, Oh B, Butow PN, Mullan BA, Clarke S: Cancer patient disclosure and patient-doctor communication of complementary and alternative medicine use: a systematic review. Oncologist 2012, 17:1475-1481.

32. Edwards A, Gray J, Clarke A, Dundon J, Elwyn G, Gaff C: Interventions to improve risk communication in clinical genetics: systematic review. Patient Educ Couns 2008, 71:4-25.

33. Edwards A, Hood K, Matthews E, Russell D, Russell I, Barker J: The effectiveness of one-to-one risk communication interventions in health care: a systematic review. MDM 2000, 20:290-297.

34. Egan M, Berube D, Racine G, Leonard C, Rochon E: Methods to Enhance Verbal Communication between Individuals with Alzheimer's Disease and Their Formal and Informal Caregivers: A Systematic Review. Int J Alzheimer's Disease 2010, 2010:1-12.

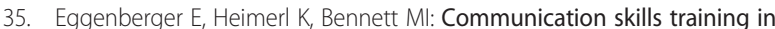
dementia care: a systematic review of effectiveness, training content, and didactic methods in different care settings. Int Psychogeriatr 2013, 25:345-358.

36. Fawole OA, Dy SM, Wilson RF, Lau BD, Martinez KA, Apostol CC: A systematic review of communication quality improvement interventions for patients with advanced and serious illness. J Gen Intern Med 2013, 28:570-577.

37. Finke $E H$, Light J, Kitko L: A systematic review of the effectiveness of nurse communication with patients with complex communication needs with a focus on the use of augmentative and alternative communication. J Clin Nurs 2008, 17:2102-2115.
38. Hancock K, Clayton JM, Parker SM, Walder S, Butow PN, Carrick S: Discrepant perceptions about end-of-life communication: a systematic review. J Pain Symptom Manage 2007, 34:190-200.

39. Harrington J, Noble LM, Newman SP: Improving patients' communication with doctors: a systematic review of intervention studies. Patient Educ Couns 2004, 52:7-16.

40. Henry SG, Fuhrel-Forbis A, Rogers MA, Eggly S: Association between nonverbal communication during clinical interactions and outcomes: a systematic review and meta-analysis. Patient Educ Couns 2012, 86:297-315.

41. Janssen SM, Lagro-Janssen AL: Physician's gender, communication style, patient preferences and patient satisfaction in gynecology and obstetrics: a systematic review. Patient Educ Couns 2012, 89:221-226.

42. Laidsaar-Powell RC, Butow PN, Bu S, Charles C, Gafni A, Lam WW: Physicianpatient-companion communication and decision-making: A systematic review of triadic medical consultations. Patient Educ Couns 2013, 91:3-13.

43. Oliveira VC, Refshauge KM, Ferreira ML, Pinto RZ, Beckenkamp PR, Negrao Filho RF: Communication that values patient autonomy is associated with satisfaction with care: a systematic review. J Physiother 2012, 58:215-229.

44. Parker SM, Clayton JM, Hancock K, Walder S, Butow PN, Carrick S: A systematic review of prognostic/end-of-life communication with adults in the advanced stages of a life-limiting illness: patient/caregiver preferences for the content, style, and timing of information. J Pain Symptom Manage 2007, 34:81-93.

45. Pinto RZ, Ferreira ML, Oliveira VC, Franco MR, Adams R, Maher CG: Patientcentred communication is associated with positive therapeutic alliance: a systematic review. J Physiother 2012, 58:77-87.

46. Rodin G, Mackay JA, Zimmermann C, Mayer C, Howell D, Katz M: Clinicianpatient communication: a systematic review. Supportive Care Cancer 2009, 17:627-644.

47. Scheunemann LP, McDevitt M, Carson SS, Hanson LC: Randomized, controlled trials of interventions to improve communication in intensive care: a systematic review. Chest 2011, 139:543-554.

48. Slort W, Schweitzer BP, Blankenstein AH, Abarshi EA, Riphagen II, Echteld MA: Perceived barriers and facilitators for general practitioner-patient communication in palliative care: a systematic review. Palliat Med 2011, 25:613-629.

49. Tay LH, Hegney D, Ang E: Factors affecting effective communication between registered nurses and adult cancer patients in an inpatient setting: a systematic review. Int J Evid Based Healthc 2011, 9:151-164.

50. Thompson L, McCabe R: The effect of clinician-patient alliance and communication on treatment adherence in mental health care: a systematic review. BMC Psychiatry 2012, 12:87

51. Uitterhoeve RJ, Bensing JM, Grol RP, Demulder PH, Van AT: The effect of communication skills training on patient outcomes in cancer care: a systematic review of the literature. Eur J Cancer Care 2010, 19:442-457.

52. Vasse E, Vernooij-Dassen M, Spijker A, Rikkert MO, Koopmans R: A systematic review of communication strategies for people with dementia in residential and nursing homes. Int Psychogeriatr 2010, 22:189-200.

53. Wanyonyi KL, Themessl-Huber M, Humphris G, Freeman R: A systematic review and meta-analysis of face-to-face communication of tailored health messages: implications for practice. Patient Educ Couns 2011, 85:348-355.

doi:10.1186/1472-6963-14-271

Cite this article as: Constand et al:: Scoping review of patient-centered care approaches in healthcare. BMC Health Services Research 2014 14:271.

\section{Submit your next manuscript to BioMed Central and take full advantage of:}

- Convenient online submission

- Thorough peer review

- No space constraints or color figure charges

- Immediate publication on acceptance

- Inclusion in PubMed, CAS, Scopus and Google Scholar

- Research which is freely available for redistribution 